November 2000

\title{
A New Application of Taylor Rules: Model Evaluation
}

\begin{abstract}
Taylor rules posit a linear relationship between the output gap, inflation, and short-term nominal interest rates. Previous work has shown that the relationship between these key economic variables as captured by the Taylor rule is quite robust both across countries and monetary policy regimes. Consequently, the Taylor rule has become a useful characterization of monetary policy with much recent work focussed on the optimal formulation of the Taylor rule and the properties of equilibrium. While this research has provided insights into the conduct of monetary policy, our interest in the Taylor rule is from a quite different perspective: we ask whether a calibrated monetary model can produce Taylor rule behavior similar to that seen in the data. That is, since the Taylor rule is a useful summary of the characteristics of a monetary economy, it seems reasonable to ask whether a monetary model, when calibrated to the data, produces a similar relationship. For our analysis, we employ a version of the limited participation model of Christiano, Eichenbaum, and Evans (1997) that permits both technology and money shocks. We find that this model, when the shock process is calibrated to US data, is able to replicate qualitatively the correlation of interest rates with inflation implied by the Taylor rule but fails dramatically to match that between nominal interest rates and output.

JEL Codes: E40, E52, E58, E30

Keywords: Taylor rule, limited participation, calibration
\end{abstract}

Kevin Salyer

Department of Economics

University of California - Davis

Davis, CA 95616

Phone: (530) 7528359

Fax: (530) 7529382

E-mail: kdsalyer@ucdavis.edu

Kristin Van Gaasbeck

Department of Economics

University of California - Davis

Davis, CA 95616

Phone: (530) 7523034

Fax: (530) 7548073

E-mail: kavan@ucdavis.edu 


\section{Introduction}

In a seminal paper, John Taylor (1993) proposed a simple rule that could be used for both positive and normative analysis of monetary policy. This rule, now referred to in the literature as "the Taylor rule", states that movements in the short term nominal interest rate are related to contemporaneous movements in inflation and output. In a regime of activist stabilization monetary policy, the movements in the short term interest rate, presumed to be the instrument of monetary policy, reflect adjustments of the real rate deemed necessary to control aggregate demand when inflation deviates from its target value and/or output departs from its full employment level. However, Taylor (1999) has recently shown that the qualitative relationship between interest rates, inflation, and output implied by the Taylor rule is also observed in monetary regimes that do not imply activist stabilization policy; e.g. a gold standard or constant money growth rate rule. Hence, while the parameters in the Taylor rule will be determined by the specific monetary regime, the general qualitative relationship between these three key economic variables appears to be quite robust.

The overwhelming majority of literature spawned by Taylor's original analysis has focused on the implications for activist monetary policy. This literature can be divided into two broad groups: historical and cross-country analysis of the conduct of monetary policy and the theoretical implications of Taylor rules. Examples of the former are: Clarida, Galí, and Gertler's (2000) recent study of monetary policy, the cross-country analysis of monetary policy rules by Clarida, Galí, and Gertler (1998), and Rudebusch and Svensson's (1999) structural analysis of optimal Taylor rules. Examples of the latter theoretical analysis are Benhabib, Schmitt-Grohe, and Uribe (1999) and Christiano and Gust (1999); these papers 
have illustrated that particular parameterizations of Taylor rules in combination with specific theoretical settings can result in unstable and/or indeterminacy of equilibrium.

The analysis presented here proposes a quite different role for Taylor rules; specifically, we employ the Taylor rule as a diagnostic for evaluating the equilibrium behavior of a calibrated monetary model. That is, given the empirical robustness of the relationship between inflation, interest rates, and output implied by the Taylor rule, it would seem desirable for a monetary model to replicate this behavior when calibrated to the data. Evaluating calibrated models is difficult and the typical analysis involves the use of impulse response functions (e.g. Christiano, Eichenbaum and Evans (1997)), or a comparison of a limited set of second moments (Cooley and Hansen (1997)). The evidence from impulse response functions relies on often dubious identification issues (see Uhlig (1999)) for a demonstration) while the use of a small set of moments to assess the model raises the question about model validity in other, perhaps equally important dimensions (a point made forcefully by Cogley and Nason's (1995) analysis of the dynamic implications of real business cycle models). While our analysis also uses a relatively small set of moments to assess the performance of the model, the set of moments (i.e. the correlations implied by the Taylor rule) are chosen because of their empirical robustness and policy interpretation.

The theoretical model we analyze is a variation of a limited participation model studied in Christiano, Eichenbaum, and Evans (1997). This model was chosen for two reasons: (1) nominal interest rates are affected by both Fisherian and liquidity factors and (2) the asymmetric impact of monetary policy (i.e. open market operations) on households vis-a-vis financial intermediaries is captured, albeit crudely. Moreover, the authors' concluded that 
this model, in comparison to a sticky-price model, more accurately replicated key features of the U.S. economy. Hence, this model would seem to be a good candidate for evaluation from the perspective of the Taylor rule. Our analysis consists of the following: using the sample period 1959:3-1998:4, we estimate the parameters of a simple Taylor rule. Then the parameters of a limited participation model that incorporates both money and technology shocks are calibrated using data from the sample period and the equilibrium is computed. Finally, the parameters of the Taylor rule implied by the artificial economy are computed and compared to those estimated from the data.

The results from this exercise are instructive: the model is able to duplicate qualitatively the relationship between inflation and nominal interest implied by the Taylor rule but fails dramatically to replicate the correlation between nominal interest rates and output. The failure is due to the fact that monetary disturbances produce a negative relationship between interest rates and output within the model while the Taylor rule states that this relationship should be positive. While technology shocks could in principle produce this positive correlation in the model, we do not find this behavior in the calibrated version. Hence, we conclude that a limited participation model that does not produce a positive relationship between technology shocks and interest rates is missing a key feature of the U.S. economy.

\section{Limited Participation Model with Technology Shocks}

For our analysis, we employ a variant of the limited participation monetary model described in Christiano, Eichenbaum, and Evans (1997). We simplify the analysis by assuming that output is produced in a single sector characterized by identical, perfectly competitive firms 
using standard technology. That is, the production function uses inputs of capital and labor and exhibits constant returns to scale; we depart, however, from the previous authors' model by assuming that production is subject to stochastic shocks. ${ }^{1}$ There are four economic agents: households, firms, financial intermediaries, and the government. These interact in factor, goods, and lending markets. Charateristic of these models, there are four critical rigidities: (i) Household's face a cash-in-advance constraint on consumption purchases. (ii) Household's make portfolio decisions before they know the state of the world (i.e. the realizations of the monetary growth rate and the technology shock) which can not be revised. (iii) The monetary injection (or tax if the growth rate is negative) is distributed directly and solely to the financial intermediaries. (iv) Firms must finance their current wage bill through loans from the banking sector. These timing assumptions and the flow of funds in the various markets are depicted in Figures 1 and 2. The choices of each agent are described in more detail below.

\footnotetext{
1 The CEE (1997) model includes an intermediate goods sector, comprised of monopolistic competitors and a final goods sector. The motivation for their set-up is to allow for comparison between sticky-price and limited-participation models.
} 


\section{Timing of Markets in the Limited Participation Model}

Households send $I_{t}$ cash deposits to the financial intermediary
Firms borrow $W_{t} N_{t}$ from the financial intermediary at gross interest rate $R_{t}$
Firms repay $R_{t} W_{t} N_{t}$ to the financial intermediary and households receive interest on their deposits at rate $R_{t}$

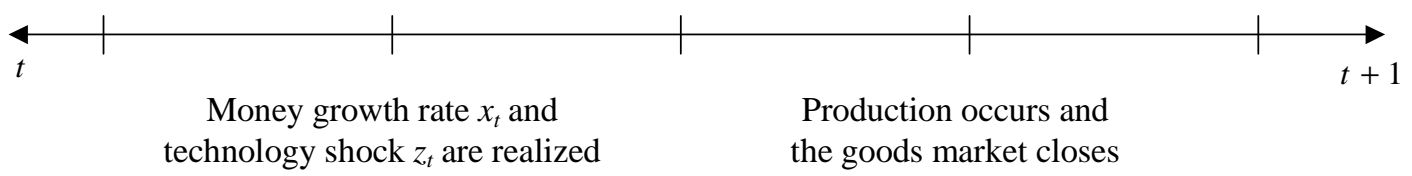

Figure 1

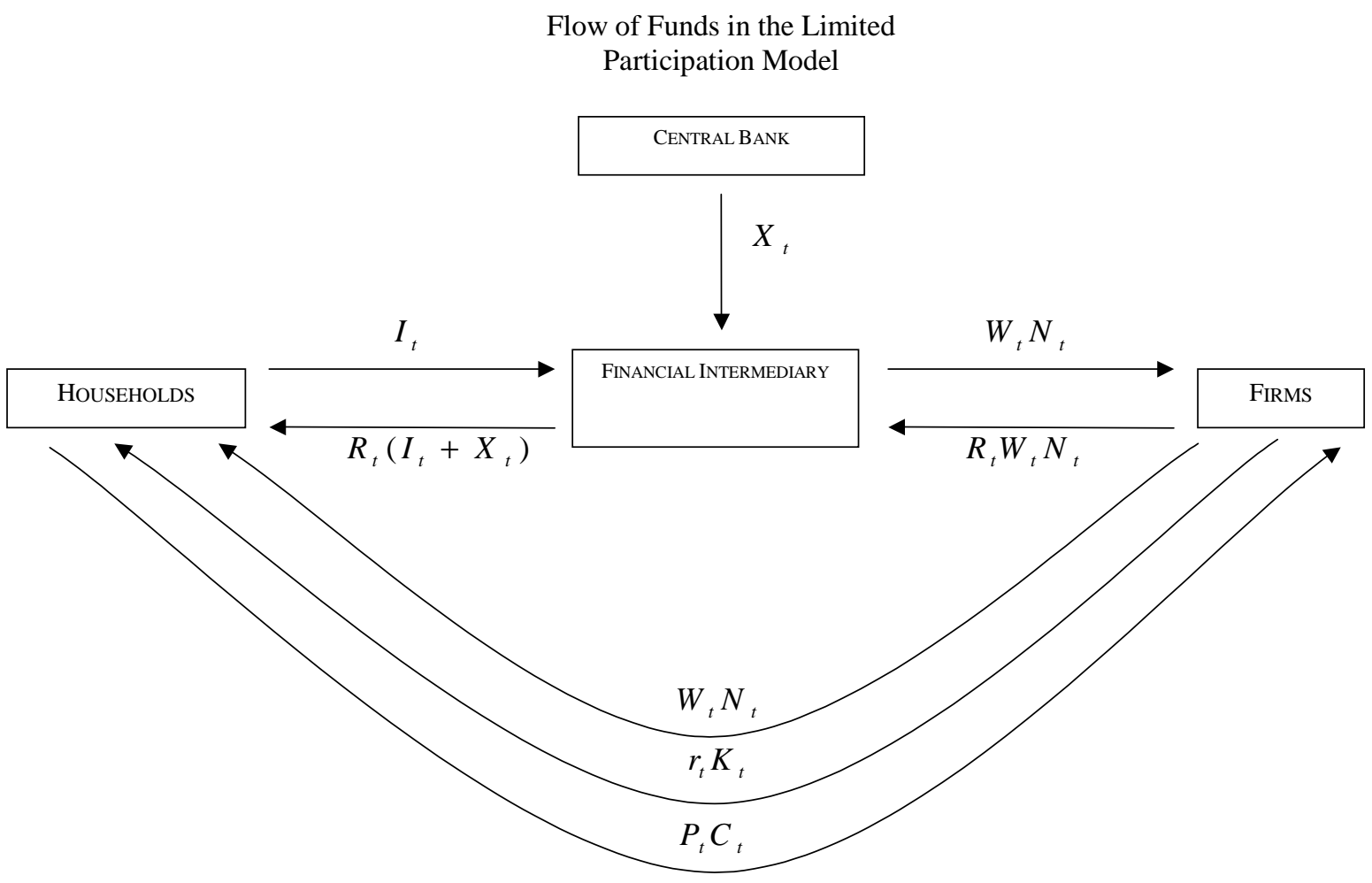

Figure 2 


\subsection{Households}

In every period, identical agents choose their time $t$ consumption, $C_{t}$, and labor hours, $N_{t}$, to maximize present discounted expected utility:

$$
E_{t} \sum_{i=0}^{\infty} \beta^{i} U\left(C_{t+i}, N_{t+i}\right)
$$

where $\beta \in(0,1)$. The utility function has the following form:

$$
U\left(C_{t}, N_{t}\right)=\log \left(C_{t}-\frac{\psi_{0}}{1+\psi} N_{t}^{1+\psi}\right)
$$

with $\psi_{0}, \psi>0$.

In addition to labor, households sell their capital to the firms. Since our interest is in the business cycle behavior of the model, our analysis focuses on the labor market. Hence, we assume all households own one unit of capital, which is supplied inelastically to firms at the nominal rental rate $r_{t}$. Moreover, the depreciation rate is zero while output is perishable and hence only used for consumption. This implies $K_{t}=1, \forall t$.

Households enter each period with cash holdings $M_{t}$ and must make their portfolio decision before the current realizations of the monetary and technology shocks are known. This decision consists of allocating $M_{t}$ between nominal balances to be used for consumption and deposits, denoted $I_{t}$, to the banking sector. The gross nominal return on deposits, denoted $R_{t}$, is determined after the state of the world is known and received after the goods market closes. Once the state is known, agents make consumption and labor decisions. Current nominal labor income, $W_{t} N_{t}$, is paid in advance of production and, hence, augments the nominal balances allocated for consumption. This implies the following cash-in-advance constraint 
on consumption purchases:

$$
P_{t} C_{t} \leq W_{t} N_{t}+M_{t}-I_{t}
$$

At the end of the period, agents receive the income from capital, the return from deposits, and the profits from the financial intermediary (these consist of the income generated by lending the monetary injection). Household money holdings are described by the following law of motion:

$$
M_{t+1}=W_{t} N_{t}+M_{t}-I_{t}-P_{t} C_{t}+r_{t} K_{t}+R_{t}\left(I_{t}+X_{t}\right)
$$

where $X_{t}$ represents the lump-sum cash injection issued by the central bank at time $t$.

Given these constraints, optimal choices of labor, consumption, and deposits must satisfy the following necessary conditions:

$$
\begin{gathered}
\frac{W_{t}}{P_{t}}=\psi_{0} N_{t}^{\psi} \\
E_{t-1}\left[\frac{U_{c, t}}{P_{t}}\right]=E_{t-1}\left\{\beta R_{t} E_{t}\left[\frac{U_{c, t+1}}{P_{t+1}}\right]\right\}
\end{gathered}
$$

Equation (5) expresses the standard result that agents' marginal rate of substitution between consumption and labor is equal to the real wage and defines an upward sloping labor-supply curve with labor supply elasticity of $1 / \psi$. The lagged expectation operator in the necessary condition associated with funds deposited in the banking sector, equation (6), expresses the fact that this decision is made at time $t$ before the current state of the world is known, i.e. with the information known in period $t-1$. 


\section{$2.2 \quad$ Firms}

Firms choose labor and capital every period in order to maximize profits; the production function is assumed to be Cobb-Douglas:

$$
Y_{t}=z_{t} K_{t}^{\alpha} N_{t}^{1-\alpha}
$$

where $\alpha \in(0,1)$. The technology shock follows a stationary first-order Markov process with unconditional mean $\mu_{z}=1$; this process will be described in more detail below. Since the firms must pay workers in advance of production, they borrow their wage bill, $W_{t} N_{t}$, from a financial intermediary. These firms repay the wage bill, at gross interest rate $R_{t}$, after revenue from production is received (at the end of the period.) Firms also pay the costs of capital to households at the end of the period.

The profit maximizing choices of $K_{t}$ and $N_{t}$ are characterized by the condition that factors are paid their marginal products. Consequently, the labor demand curve in the economy is defined as (the equilibrium condition that $K_{t}=1$ has been used)

$$
R_{t} \frac{W_{t}}{P_{t}}=(1-\alpha) \frac{z_{t}}{N_{t}^{\alpha}}
$$

The labor supply and labor demand curves, i.e. equations (5) and (8) respectively, can be combined to yield the following expression characterizing equilibrium in the labor market:

$$
R_{t}=\frac{(1-\alpha)}{\psi_{0}} z_{t} N_{t}^{-(\psi+\alpha)}
$$




\subsection{Financial Intermediary}

The financial intermediary in this economy provides loans to the firms using the deposits from households and new money distributed by the central bank. Banks incur no costs implying that loans are inelastically supplied to firms; the interest rate adjusts so that the following market clearing condition holds in equilibrium:

$$
W_{t} N_{t}=I_{t}+X_{t}
$$

The demand for funds derives from firms' wage bills, $W_{t} N_{t}$, which they borrow before production occurs. The demand for funds, $F^{D}$, can be expressed by using equation(8) and the corresponding necessary condition for capital $\left(r_{t}=\alpha z_{t} N_{t}^{1-\alpha}\right)$ to yield:

$$
F_{D} \equiv W_{t} N_{t}=\frac{(1-\alpha)}{\alpha} \frac{r_{t}}{R_{t}}
$$

Equation (11) expresses a static downward-sloping demand for funds in $R-F$ space. Upon payment of the loan, the financial intermediary returns $R_{t} I_{t}$ (in return for deposits) and $R_{t} X_{t}$ (as profits) to households, as described in equation (4).

The cash-in-advance constraint, equation (3), is assumed to be binding in all periods. Combining this condition with the equilibrium condition from the loan market equation (10) permits market clearing in the goods markt to be expressed as:

$$
P_{t} C_{t}=M_{t}+X_{t}
$$


or, since $Y_{t}=C_{t}$ at equilibrium:

$$
P_{t}=\frac{M_{t}+X_{t}}{Y_{t}}
$$

Consequently, equilibrium velocity is always unity when defined in terms of the end-ofperiod money stock. Combining equations (9) and (13) yields the following expression:

$$
\frac{W_{t} N_{t}}{P_{t} C_{t}}=\frac{I_{t}+X_{t}}{M_{t}+X_{t}}
$$

This expression represents the ratio of funds passing through the loan to goods markets. Note that this ratio is monotonically increasing in the monetary transfer, $X_{t}$. The implication for nominal interest rates can be seen by using equation (8) and the resource constraint, $C_{t}=z_{t} N_{t}^{1-\alpha}$, to rewrite the left-hand side of equation (14) to yield:

$$
\frac{(1-\alpha)}{R_{t}}=\frac{I_{t}+X_{t}}{M_{t}+X_{t}}
$$

Clearly, increased liquidity in the loan market (i.e. an increase in $X_{t}$ ) will cause interest rates to fall. ${ }^{2}$

\subsection{Central Bank}

The sole purpose of the central bank is to provide money to the financial sector. The growth rate of money is defined as:

$$
x_{t} \equiv \frac{X_{t}}{M_{t}}=\frac{\left(M_{t+1}-M_{t}\right)}{M_{t}}
$$

The money growth rate, $x_{t}$, like the technology shock follows a stationary Markov process; this is described in the next section.

\footnotetext{
${ }^{2}$ Note that, in equation (15), both $I_{t}$ and $M_{t}$ are predetermined when the current value of $X_{t}$ is realized.
} 


\section{Calibration}

In order to solve the model, parameter values for preferences $\left(\beta, \psi, \psi_{0}\right)$ and technology $(\alpha)$ are needed; in addition, the Markov process for the shocks must be specified. The preference and technology parameters are borrowed from Christiano, Eichenbaum, and Evans (1997) with the following values used: the discount factor, $\beta$, is set equal to 0.9926 , the capital share $\alpha$ is 0.36 , and the elasticity of labor supply, $\frac{1}{\psi}$, is set to 1 . The parameter $\psi_{0}$ is determined such that the steady state value for labor, $\bar{N}$, is unity.

The Markov process for the money and technology shocks is assumed to be a discrete state process in which the monetary growth rate can take on three values $\left(x_{1}<x_{2}<x_{3}\right)$ while the technology shock can take on two values $\left(z_{1}<z_{2}\right)$. Consequently, the state, $s_{k}=\left(x_{i}, z_{j}\right), k=i, j$ with $i=1,2,3 ; j=1,2$, is described by a 6 -state Markov process. We calibrate the parameters of this process using quarterly data from 1959:3 to 1998:4. ${ }^{3}$ A complete description of the data is provided in the Data Appendix.

The Solow residual is used as the measure of technology shocks. The residual is constructed from the following equation:

$$
\log \left(S R_{t}\right)=\log \left(Y_{t}\right)-\alpha \log \left(K_{t}\right)-(1-\alpha) \log \left(N_{t}\right)
$$

where $Y_{t}$ is real gross domestic product, $K_{t}$ is the capital stock, and $N_{t}$ is aggregate hours of wage and salary earners on non-farm payrolls. ${ }^{4} \quad$ All variables are in per-capita terms.

\footnotetext{
${ }^{3}$ We also examined two sub-samples of the data that excluded the period of non-borrowed reserves targeting (i.e. 1979:3-1982:1). Results were broadly consistent across sample periods so that, in the interest of brevity, we present the full sample results only.

${ }^{4}$ The capital stock was calculated using the perpetual inventory method, using data from 1947:1 to 1998:4. The investment series is seasonally-adjusted fixed private nonresidential investment and quarterly depreciation is assumed to be $2.0 \%$.
} 
The Solow residual is then linearly detrended and the technology shock, $\log \left(z_{t}\right)$, is measured as the detrended series.

We use the adjusted monetary base as the measure for money supply in the model. Given that the monetary base is defined as currency plus reserves, this measure of money supply most closely matches that in the model. The percentage change in the monetary base is identified as $x_{t}$.

The six possible states in each period are defined as follows:

$$
\begin{array}{ll}
s_{1}=\left(x_{1}, z_{1}\right) & s_{4}=\left(x_{1}, z_{2}\right) \\
s_{2}=\left(x_{2}, z_{1}\right) & s_{5}=\left(x_{2}, z_{2}\right) \\
s_{3}=\left(x_{3}, z_{1}\right) & s_{6}=\left(x_{3}, z_{2}\right)
\end{array}
$$

where $x_{j}$ and $z_{j}$ are the realizations of the monetary growth and technology shocks, respectively. To determine the state, we partition the data using the sample means of both shocks, $\bar{x}$ and $\bar{z}$, and standard deviation of the monetary shock, $\delta$ in the following manner:

$$
\begin{array}{ll}
s_{1} \text { if }\left(x_{t} \leq \frac{\bar{x}-\delta}{2}\right. & \text { and } \left.z_{t} \leq \bar{z}\right) \\
s_{2} \text { if }\left(\frac{\bar{x}-\delta}{2}<x_{t} \leq \frac{\bar{x}+\delta}{2}\right. & \text { and } \left.z_{t} \leq \bar{z}\right) \\
s_{t}= & \text { and } \left.z_{t} \leq \bar{z}\right) \\
s_{3} \text { if }\left(x_{t}>\frac{\bar{x}+\delta}{2}\right. & \text { and } \left.z_{t}>\bar{z}\right) \\
s_{5} \text { if }\left(\frac{\bar{x}-\delta}{2}<x_{t} \leq \frac{\bar{x}+\delta}{2}\right. & \text { and } \left.z_{t}>\bar{z}\right) \\
s_{6} \text { if }\left(x_{t}>\frac{\bar{x}+\delta}{2}\right. & \text { and } \left.z_{t}>\bar{z}\right)
\end{array}
$$

The transition probabilities are calculated using the appropriate relative frequency measure; i.e. we use the following specification:

$$
\pi_{i j}=\frac{n_{i j}}{\sum_{k=1}^{6} n_{i k}}
$$


where $n_{i j}$ is the number of times state $i$ is followed by state $j$ in the sample. Finally, the values for $\left(x_{i}, z_{j}\right)$ are determined by the means of the partitioned data; e.g. $x_{1}$ is the mean of the monetary growth rate for values that satisfy $x_{t} \leq \frac{\bar{x}-\delta}{2}$.

To assess how well this parameterization captures the time series properties of the shocks, the implied unconditional means, standard deviations, and first-order autocorrelations of each series were computed; in addition, the contemporaneous correlations between shocks were calculated. The moments implied by the Markov process are compared to the sample moments in Table 1. The parameterization matches the moments fairly well. However, the magnitudes of the cross correlations are much weaker than observed while the autocorrelations for both shocks are slightly weaker than those observed in the data.

\section{Results}

Since portfolio decisions are made before the current state is known, the quantity of funds going to the financial intermediary will be a function of the state (determined by the realization of the shocks) at time period $t-1$. Hence, there will be six values for this quantity denoted $i_{k}=I_{t} / M_{t}$. (The nominal quantity of funds is scaled by the beginning of period money stock to achieve stationarity.) The remaining variables will be functions of both the current (denoted $k^{\prime}$ ) and previous state (denoted $k$ ), hence, equilibrium is determined by 36 values for labor, $N_{k k^{\prime}}, 36$ interest rates, $R_{k k^{\prime}}$, and 6 values for investment, $i_{k}$. These values are the solutions to 78 non-linear equations. Six equations are given by the intertemporal efficiency condition which, by using the binding cash-in-advance constraint and functional form for preferences, can be written as: 


$$
F_{k}=\beta E_{k}\left[\frac{R_{k k^{\prime}} F_{k^{\prime}}}{\left(1+x_{k^{\prime}}\right)}\right]
$$

where $E_{k}$ denotes the expectations operator conditional on the state $k$ and

$$
F_{k} \equiv E_{k}\left[\frac{1}{\left(1+x_{k^{\prime}}\right)-\left(\frac{i_{k}+x_{k^{\prime}}}{1+\psi}\right)}\right]
$$

The market clearing condition for the labor market provides 36 additional restrictions:

$$
R_{k k^{\prime}}=\frac{(1-\alpha)}{\psi_{o}} z_{k^{\prime}} N_{k k^{\prime}}^{-(\alpha+\psi)}
$$

Finally, the ratio of funds in the goods and lending markets (equation (14)) yields an additional 36 equations which can be written as:

$$
\psi_{0} N_{k k^{\prime}}^{\alpha+\psi}=z_{k^{\prime}}\left(\frac{i_{k}+x_{k^{\prime}}}{1+x_{k^{\prime}}}\right)
$$

These values imply the solutions for the other variables $\left(P_{t}, Y_{t}, w_{t}\right)$ in the economy where $w_{t}$ is the real wage. Note that equation (20) can be used in equation (19) to yield:

$$
R_{k k^{\prime}}=(1-\alpha)\left(\frac{1+x_{k^{\prime}}}{i_{k}+x_{k^{\prime}}}\right)
$$

Critically, the implication of the above expression is that interest rates are independent of technology shocks.

\subsection{Response to shocks}

This section includes the responses of $R_{t}, N_{t}, P_{t}, Y_{t}$, and $w_{t}$, to the monetary and technology shocks. Following Christiano, Eichenbaum, and Evans (1997), the response of variable $v_{t}=$ $\left(N_{t}, Y_{t}, P_{t}, w_{t}\right)$ to a shock $s_{t}$ is measured as an elasticity:

$$
d v=\frac{\log \left(\frac{v_{t+1}}{v_{t}}\right)}{\log \left(\frac{s_{t}}{s_{t+1}}\right)}
$$


where $v_{t}$ is the value of the variable in state $\left(s_{t-1}, s_{t}\right)$ and $v_{t+1}$ is the realization in state $\left(s_{t+1}, s_{t}\right)$. The response of the interest rate is in semi-elasticity form:

$$
d R=\frac{R_{t+1}-R_{t}}{\log \left(\frac{s_{t}}{s_{t+1}}\right)}
$$

Table 2 presents this characterization of equilibrium behavior.

Qualitatively, the responses to a monetary expansion in Table 2 match those found by Christiano, Eichenbaum, and Evans (1997). The elasticities are slightly weaker here, because of the absence of fixed costs and markups. The price and output elasticties sum to one due to velocity being constant; also, the response of labor and the real wage are the same because the labor supply elasticity, $\frac{1}{\psi}$, is set to unity.

The liquidity effect is clearly evident - for example, a monetary injection from the central bank increases in the supply of available funds to firms requiring a fall in the interest rate to clear the funds market. The resulting fall in labor costs causes an increase in labor hours and output. The increase in output is less than the increase in the money supply so prices increase as well.

The responses to a technology shock match what we expect: a positive shock increases the demand for labor, boosting employment, output, and real wages. The responses of prices and output are again dictated by constant monetary velocity. Note that, as implied by equation (21), the interest rate is not affected by technology shocks; this is due to the fact that consumption is not present in the agent's marginal rate of substitution between consumption and leisure and the assumption of unitary elasticity of labor supply. 


\section{Monetary Policy Rules}

\subsection{Estimated Taylor Rules}

While the behavior of the limited participation model reported in Table 2 is a useful characterization of its equilibrium properties, our interest lies in those properties captured by the Taylor rule. To explore this further, it is necessary to specify and estimate the coefficients of a Taylor rule from the data. Specifically, we use the following specification for the Taylor rule:

$$
R_{t}=\alpha+\beta \tilde{y}_{t}+\gamma \pi_{t}+\rho R_{t-1}
$$

where $\tilde{y}_{t}$ is the output gap, $\pi_{t}$ is the average inflation rate over the current and previous three quarters (calculated using the implicit price deflator for output), and $R_{t}$ is identified as the Federal Funds rate. Taylor (1993) excluded the lagged interest rate term and recommended that $\beta$ and $\gamma$ be set equal to 0.5 and 1.5 in his original study. The subsequent literature has produced many variations on this theme such as using lagged values for output and inflation (Christiano and Gust (1999)), the expected inflation rate (Clarida, et al (1998, 2000)), and including lagged interest rates in order to capture interest rate smoothing. For our analysis, we use a simple form of the rule (including the lagged interest rate) and estimate the parameters using data from the sample period. We include the lagged interest rate for two reasons. First, the inclusion of lagged interest rates captures central bank interest-rate smoothing evident from strong positive autocorrelation in the money market rate. Also, including this term improves both the econometric fit and properties of the residuals. ${ }^{5}$

A critical step in estimating equation (22) is measuring the output gap, defined as the

\footnotetext{
${ }^{5}$ Exclusion of the lagged interest rate term induces serially correlated errors.
} 
percentage deviation of output from its potential or trend value. ${ }^{6} \quad$ We use four different definitions of this measure: log-linear detrending, log-linear detrending using recursive least squares (or recursive residuals), Congressional Budget Office estimates, and real-time estimates.

The traditional method of estimating the output gap assumes that the log of output follows a linear or quadratic trend. The difficulty with this definition is that future information about the path of output, not available to policymakers, is used to predict the Federal Funds rate in any given period. If the Taylor rule does in fact model monetary policy, using future information could bias the coefficient on the output gap. Alternatively, one could maintain the assumption of a linear trend while using a recursive estimation procedure to ensure that only information available up to time $t$ is used in estimating potential output. The (recursive) residuals from this regression measure the output gap each period.

The Congressional Budget Office's (CBO) structural estimate of quarterly potential GDP avoids these problems. The CBO estimates potential output using a structural model of the economy with current and lagged variables as inputs. We define the output gap as percentage deviations of GDP from the CBO potential GDP series.

The CBO estimates are, however, subject to historical revision implying that the published data are not consistent with the information available to policymakers. To avoid this source of error in measuring the output gap, Orphanides, et. al. (1999) and Orphanides and

\footnotetext{
${ }^{6}$ As stressed by Orphanides (1998), another complication is the difference between published and real-time data, i.e. the data available to policymakers at the time of policy decisions. While we note that real-time estimates of both inflation and the output gap should be used, we focus entirely on measures of the output gap. In part, our decision to use the published series for inflation is based upon the result that using lagged values for this series does not significantly affect the parameter estimates (see Rudebusch and Svensson (1999) and McCallum and Nelson (1999)).
} 
Norden (1999) use vintage data to measure errors in estimating the output gap. Orphanides and Norden (1999) show that problems associated with measuring the output gap derive mainly from poor real-time estimates rather than revisions in published historical data. As shown below, our results are consistent with this finding.

To address this issue, we estimate the output gap using real-time data, presented in the fourth panel of each table. We extend the Crushore and Stark (1999) data set to include the 1959:3-1965:4 period. ${ }^{7}$ The real-time data set reports published quarterly statistics available at the beginning of each quarter (or each month). We estimate the output gap by fitting GDP to a log-linear trend to the real GDP series available each quarter, 1959:3-1998:3. The real-time estimates are subject to neither historical revision nor the problem of using future information to estimate potential output.

\subsection{Results}

Tables 3 presents the coefficient estimates over the sample period 1959:3-1998:4. The estimated coefficients are similar for three of the four methods used to identify the output gap. The traditional method of estimating the output gap, linear detrending, differs significantly from the rest of the estimates. We take this results as being suggestive that using future information to estimate potential output results in a poor measure of the output gap relevant to policymakers. Also, this suggests that historical revisions do not significantly affect Taylor-rule estimates. The important feature to note, however, is that, regardless of the definition of the output gap, the coefficients on both inflation and the output gap are

\footnotetext{
7 The Crushore and Stark (1999) data set reports statistics available on a monthly or quarterly basis. We use data for real GDP reported in February, May, August, and November from November 1965-February 1999. We then fit a log-linear trend to real GDP for each available data set to derive the most recent estimate of the output gap.
} 
positive.

\subsection{Taylor Rule in the Limited Participation Model}

The Taylor rule coefficients implied by the limited participation model are next computed using the moments of the equilibrium unconditional distribution of the model. ${ }^{8}$ The coefficients from two versions of the rule (differentiated by whether or not the lagged interest rate is included) are presented in Table 4. The important result is that the model is incapable of producing Taylor rule coefficients similiar to that observed in the data. While the coefficient on inflation has the correct sign, it is much smaller than that estimated from the data. Even more problematic is that the model produces a negative coefficient on output. This is due to two factors: the liquidity effect and that fact that technology shocks do not affect interest rates. Hence, in equilibrium the correlation between interest rates and output are necessarily negative.

\section{Conclusion}

The lack of a well-specified metric makes assessment of calibrated models difficult. The standard procedure is to examine the equilibrium properties of the model within a limited set of dimensions implying that the choice of dimensions is critical We argue that a useful selection procedure is to examine model behavior along dimensions that are consistent with

${ }^{8}$ We compute the coefficients using the following system of equations:

$$
\begin{aligned}
\operatorname{cov}\left(R_{t}, y_{t}\right) & =\beta \operatorname{var}\left(y_{t}\right)+\gamma \operatorname{cov}\left(y_{t}, \pi_{t}\right)+\rho \operatorname{cov}\left(y_{t}, R_{t-1}\right) \\
\operatorname{cov}\left(R_{t}, \pi_{t}\right) & =\beta \operatorname{cov}\left(\pi_{t}, y_{t}\right)+\gamma \operatorname{var}\left(\pi_{t}\right)+\rho \operatorname{cov}\left(\pi_{t}, R_{t-1}\right) \\
\operatorname{cov}\left(R_{t}, R_{t-1}\right) & =\beta \operatorname{cov}\left(R_{t-1}, y_{t}\right)+\gamma \operatorname{cov}\left(R_{t-1}, \pi_{t}\right)+\rho \operatorname{var}\left(R_{t-1}\right)
\end{aligned}
$$

where the variables are in deviation form. This is equivalent to the system of equations used to derive least squares estimates. Output in the model is equivalent to the output gap in the data because output is stationary in the model. 
policy analysis. Here we use this selection criteria to explore the behavior of a calibrated limited participation model from the vantage point of the Taylor rule. This rule has proved to be a useful characterization of monetary policy and extensive empirical research has shown that, across countries and over time, the coefficients in the rule are positive.

In contrast, we demonstrate that the calibrated version of the limited participation model that we analyze implies that the coefficient on the output gap is negative. This result appears to be driven by the defining feature of the limited participation framework; i.e. the liquidity effect on nominal interest rates. While, in theory, technology shocks could overturn this result, the model studied here does not do so. The limited participation model captures important aspects of monetary policy, but its inability to produce Taylor rule behavior represents a significant limitation. Clearly, additional research is needed to determine what additional features need to be appended to this model to generate consistent equilibrium behavior. 


\section{Appendices}

\subsection{Appendix 1 - Parametrization of the Markov process}

Using the method described in the paper, the following Markov process for the money and technology shocks is estimated from the data:

$$
\begin{gathered}
\left(\begin{array}{l}
x_{1} \\
x_{2} \\
x_{3} \\
z_{1} \\
z_{2}
\end{array}\right)=\left(\begin{array}{c}
0.0069 \\
0.0161 \\
0.0235 \\
0.9728 \\
1.0149
\end{array}\right) \Pi=\left(\begin{array}{cccccccc}
0.7222 & 0.1667 & 0.0000 & 0.05555 & 0.05555 & 0.0000 \\
0.0882 & 0.6471 & 0.1471 & 0.0000 & 0.0588 & 0.0588 \\
0.0526 & 0.2632 & 0.5790 & 0.0000 & 0.0526 & 0.0526 \\
0.0000 & 0.0476 & 0.0000 & 0.5238 & 0.3810 & 0.0476 \\
0.0000 & 0.0256 & 0.0256 & 0.2308 & 0.4872 & 0.2308 \\
0.0000 & 0.0769 & 0.0769 & 0.0000 & 0.3077 & 0.5385
\end{array}\right) \\
P=(0.0904,0.2112,0.1229,0.1351,0.2570,0.1834) \\
\end{gathered}
$$

The $x_{j}$ and $z_{j}$ denote the conditional mean for monetary base growth and technology shocks in state $j$ while $\Pi$ and $P$ are the transition probability matrix and vector of unconditional probabilities, respectively. 


\subsection{Appendix 2 - Data}

The following series were obtained from the US-ECON data set provided by Haver Analytics.

1. GDPH - Gross domestic product (seasonally adjusted at annual rates, billions of chain-weighted 1992 dollars)

2. FNH - Fixed, non-residential investment (seasonally adjusted at annual rates, billions of chain-weighted 1992 dollars)

3. LHTNAGRA - Aggregate hours, wage \& salary workers on non-agricultural payrolls (seasonally adjusted at annual rates, millions of hours)

4. LNT20N - Civilian noninstitutional population, both sexes, 20 years and over (thousands, non-seasonally adjusted)

5. FARAM - Monetary base, adjusted for changes in reserve requirements (seasonally adjusted, millions of dollars)

6. DGDP - Implicit price deflator, gross domestic product (seasonally adjusted)

7. FFED - Federal Funds rate (effective)

8. GDPPOTHQ - Real potential gross domestic product $\{\mathrm{CBO}\}$ (billions of chainweighted 1992 dollars)

In addition, we used the real output series (ROUTPUT), available from November 1965February 1999, from the Crushore and Stark (1999) real-time data set. To extend the data series for our sample, we used the real output series reported in the publication BEA's Survey of Current Business 


\section{References}

Benhabib, Jess, Stephanie Schmitt-Grohe, and Martin Uribe, "The Perils of Taylor Rules," mimeo (1999).

Bureau of Economic Analysis, BEA's Survey of Current Business, 1958-1965.

Christiano, Lawrence, Martin Eichenbaum, and Charles Evans, "Sticky Price and Limited Participation Models of Money: A Comparison," European Economic Review 41 (1997), 1201-1249.

Christiano, Lawrence and Christopher Gust, "Taylor Rules in a Limited Participation Model," NBER Working Paper 7017 (1999)

Clarida, Richard, Jordi Galí, and Mark Gertler, "Monetary Policy Rules in Practice: Some International Evidence," European Economic Review 42 (1998), 1033-1067.

Clarida, Richard, Jordi Galí, and Mark Gertler "Monetary Policy Rules and Macroeconomic Stability: Evidence and Some Theory," Quarterly Journal of Economics (2000), 147-180.

Cogley, Timothy and James Nason, "Output Dynamics in Real Business Cycle Models," American Economic Review (1995), 492-511.

Congressional Budget Office, "CBO's Method for Estimating Potential Output," $C B O$ Memorandum (1995).

Cooley, Thomas, and Gary Hansen, "The Role of Monetary Shocks in Equilibrium Business Cycle Theory: Three Examples," European Economic Review 42 (1998), 605617.

Crushore, Dean and Tom Stark, "A Real-Time Data Set for Macroeconomists," Federal Reserve Bank of Philadelphia Working Paper 99-4 (1999).

Judd, John and Glenn Rudebusch, "Taylor's Rule and the Fed: 1970-1997," FRBSF Economic Review 3 (1998), 3-16.

McCallum, Bennett, and Edward Nelson, "Performance of Operational Policy Rules in an Estimated Semiclassical Structural Model," in J. Taylor, ed. Monetary Policy Rules (Chicago: Chicago University Press, 1999),15-54.

Meulendyke, Ann-Marie, U.S. Monetary Policy and Financial Markets, Federal Reserve Bank of New York (1998).

Orphanides, Athanasios, "Monetary Policy Evaluation with Noisy Information," Board of Governors of the Federal Reserve System, mimeo (1998).

Orphanides, Athanasios, "Activist Stabilization Policy and Inflation: The Taylor Rule in the 1970s," Board of Governors of the Federal Reserve System, mimeo (2000). 
Orphanides, Athanasios, and Simon van Norden, "The Reliability of Output Gap Estimates in Real Time," Board of Governors of the Federal Reserve System, mimeo (1999).

Orphanides, Athanasios, Richard Porter, David Reifschneider, Robert Tetlow, and Frederico Finan, "Errors in Measurement of the Output Gap and the Design of Monetary Policy," Board of Governors of the Federal Reserve System, mimeo (1999).

Rotemberg, Julio, and Michael Woodford, "Interest Rate Rules in an Estimated Sticky Price Model," in J. Taylor, ed. Monetary Policy Rules (Chicago: Chicago University Press, 1999), 57-119.

Rudebusch, Glenn, and Lars Svensson, "Policy Rules for Inflation Targeting," in J. Taylor, ed. Monetary Policy Rules (Chicago: Chicago University Press, 1999), 203253.

Taylor, John, "Discretion Versus Policy Rules in Practice," Carnegie-Rochester Conference Series on Public Policy 39 (1993), 195-214.

Taylor, John, "A Historical Analysis of Monetary Policy Rules," in J. Taylor, ed. Monetary Policy Rules (Chicago: Chicago University Press, 1999), 319-341.

Uhlig, Harold, "What are the Effects of Monetary Policy on Output?: Results from an Agnostic Identification Procedure," Tilberg University, CentER Working Paper 199928 (1999) 
Table 1: Moments from Parameterized Markov Process

MODEL 1

DATA

\begin{tabular}{lcc|cc}
\hline & Monetary Shocks & Technology Shocks & Monetary Shocks & Technology Shocks \\
\hline \hline Mean & 0.0161 & 0.0011 & 0.0160 & 0.0000 \\
Std. Deviation & 0.0053 & 0.0135 & 0.0068 & 0.0178 \\
Corr $\left(\mathrm{y}_{\mathrm{t}}, \mathrm{y}_{\mathrm{t}+1}\right)$ & 0.5227 & 0.8058 & 0.7184 & 0.9141 \\
Corr $\left(\mathrm{x}_{\mathrm{t}}, \mathrm{w}_{\mathrm{t}}\right)$ & -0.0198 & -0.0198 & 0.1778 & 0.1778 \\
\hline
\end{tabular}

Table 2: Responses to Monetary and Technology Shocks

Monetary Policy Shock

\begin{tabular}{cccccc}
\hline value of other shock & \multicolumn{7}{c}{} \\
\hline \hline & $d R$ & $d N$ & $d P$ & $d Y$ & $d w$ \\
\hline$z_{1}$ & -0.5998 & 0.4335 & 0.7225 & 0.2775 & 0.4335 \\
$z_{2}$ & -0.6099 & 0.4388 & 0.7192 & 0.2808 & 0.4388 \\
\hline \multicolumn{7}{c}{ Technology Shock } \\
\hline$x_{i}$ & $d R$ & $d N$ & $d P$ & $d Y$ & $d w$ \\
\hline \hline
\end{tabular}

* Indicates conditional value of other shock. The value of the money shock had no influence on effects of the technology shock 
Table 3: Estimated Taylor Rules

\section{Congressional Budget Office estimates}

\begin{tabular}{l|cccc} 
Variable & Coefficient & Std. Error & t-Statistic & Prob. \\
\hline C & 0.1472 & 0.1792 & 0.8214 & 0.4127 \\
\hline FFED(-1) & 0.9041 & 0.0341 & 26.4963 & 0.0000 \\
\hline YGAP & 0.1453 & 0.0321 & 4.5201 & 0.0000 \\
\hline INFAVG & 0.5498 & 0.1830 & 3.0038 & 0.0031 \\
\hline \hline
\end{tabular}

Log-linear trend

\begin{tabular}{l|cccc} 
Variable & Coefficient & Std. Error & t-Statistic & Prob. \\
\hline C & 0.7245 & 0.2476 & 2.9266 & 0.0040 \\
\hline FFED(-1) & 0.8728 & 0.0356 & 24.4846 & 0.0000 \\
\hline YGAP & 0.0367 & 0.0142 & 2.5802 & 0.0108 \\
\hline INFAVG & 0.1228 & 0.2316 & 0.5303 & 0.5967 \\
\hline \hline
\end{tabular}

\section{Recursive residuals}

\begin{tabular}{l|rrrl} 
Variable & Coefficient & Std. Error & t-Statistic & Prob. \\
\hline C & 0.3176 & 0.1832 & 1.7334 & 0.0851 \\
\hline FFED(-1) & 0.9138 & 0.0354 & 25.7984 & 0.0000 \\
\hline YGAP & 0.1192 & 0.0304 & 3.9186 & 0.0001 \\
\hline INFAVG & 0.6020 & 0.1908 & 3.1549 & 0.0019 \\
\hline \hline
\end{tabular}

Real-time estimates

\begin{tabular}{l|rrrl} 
Variable & Coefficient & Std. Error & t-Statistic & Prob. \\
\hline C & 0.3389 & 0.1758 & 1.9278 & 0.0557 \\
\hline FFED $(-1)$ & 0.9057 & 0.0336 & 26.9335 & 0.0000 \\
\hline YGAP & 0.1568 & 0.0302 & 5.1872 & 0.0000 \\
\hline INFAVG & 0.7331 & 0.1874 & 3.9115 & 0.0001 \\
\hline
\end{tabular}


Table 4: Implied Taylor Rule Coefficients

\begin{tabular}{lc} 
Output gap & -2.16915 \\
Inflation & 0.00012 \\
\hline \hline & \\
Output gap & -2.16922 \\
Inflation & -0.00012 \\
Lagged Interest Rate & 0.00006 \\
\hline
\end{tabular}

